\title{
Colorectal Neuroendocrine Carcinoma
}

National Cancer Institute

\section{Source}

National Cancer Institute. Colorectal Neuroendocrine Carcinoma. NCI Thesaurus. Code C96156.

An aggressive, high-grade and poorly differentiated carcinoma with neuroendocrine differentiation that arises from the colon or rectum. The mitotic count is more than 20 per 10 HPF. According to the size of the malignant cells, the prominence of the nucleoli, and the amount of cytoplasm, it is classified either as small or large cell neuroendocrine carcinoma. 